\title{
On the Relevance and Composition of Gifts within the Firm: Evidence from Field Experiments
}

\author{
Charles Bellemare* $\quad$ Bruce Shearer ${ }^{\dagger}$
}

February 9, 2009

\begin{abstract}
We investigate the economic relevance and the composition of gifts within a firm where output is contractible. We develop a structural econometric model that identifies workers' optimal reaction to monetary gifts received from their employer. We estimate the model using data from two separate field experiments, both conducted within a tree-planting firm. We use the estimated structural parameters to generalize beyond the experiment, simulating how workers would react to different gifts on the part of the firm, within different labour-market settings. We find that gifts have a role to play within this firm, increasing in importance when the workers' outside alternatives deteriorate. Profit-maximizing gifts would increase profits within slack labour markets by up to $10 \%$ on average and by up to $17 \%$ for certain types of workers. These gifts represent significant increases in worker earnings; the average gift paid to workers attains $22 \%$ of average expected earnings in the absence of gifts. We find that gifts should be given by setting piece-rates above the market-clearing level rather than through fixed wages.
\end{abstract}

JEL Codes: J33, M52, C93

Keywords: Gift giving, structural models, field experiments.

\section{Introduction}

Economists are paying increasing attention to the role that gift giving can play within the firm. Theoretical models (dating to Akerlof, 1982) suggest that gifts induce reciprocal worker effort, implying that gift giving can be part of a firm's personnel policy. Experimental studies (both laboratory and field) have shown that workers do respond to monetary

\footnotetext{
*Département d'économique, Université Laval, CIRPÉE and IZA.\{email: Charles.Bellemare@ecn.ulaval.ca\} .

${ }^{\dagger}$ Département d'économique, Université Laval, CIRPÉE and IZA. \{email: Bruce.Shearer@ecn.ulaval.ca\}. We thank Sabine Kröger, Ernst Fehr, seminar participants at McGill University, the University of Ottawa, and Laval University for comments. We acknowledge research support from SSHRC and FQRSC and the Canada Research Chair in Social Policies and Human Resources at the Université Laval.
} 
gifts from their employer, at least in the short run, by increasing their productivity (see, for example, Fehr, Kirchsteiger and Reidl, 1993; Gneezy and List, 2006; Bellemare and Shearer, 2009). However, a positive reaction of workers to gifts does not guarantee that gift-giving is a profitable policy option for the firm - the value of marginal effort to the firm may be less than the value of the gift.

Experiments which calculate treatment effects can evaluate profitability only within a specific environment, and have provided mixed evidence on this issue (eg. Fehr, Kirchsteiger and Reidl, 1993; Gneezy and List, 2006). ${ }^{1}$ However, experimental gifts are typically chosen by researchers, not the firm. What is more, the lack of profitability of a specific gift, within a specific economic environment, does not rule out the economic relevance of giftgiving in general - other gifts, not observed within a particular experiment, may generate profits.

In this paper, we consider the economic return to gift-giving within a tree-planting firm where output is contractible, allowing the firm to pay their workers piece rates. Our econometric analysis is based on field experiments conducted within the firm. We define gifts to be changes in the contract that increase worker utility and are explained to the workers as acts of kindness. We investigate whether gifts have an economic role to play within this contracting environment, and if so, under what economic conditions. We also consider the composition of the gift; when output is contractible gifts can be given through base wages and/or increases in the piece rate. We generalize the definition of a gift to take account of its composition and consider the performance of different types of gifts.

Characterizing the firm's economic return to gifts requires observing (or predicting) the response of workers to different gifts, under different economic conditions. Repeated experiments may not be practical in this regard, particularly in the field. Most experimental work on gifts seeks to isolate the response to the gift from the response to future surpluses within the firm. Consequently, gifts are presented as one-time-events (Gneezy and List (2006)), precluding repeated experiments. As well, most field experiments seek to avoid Hawthorne Effects ${ }^{2}$ by keeping workers ignorant of the fact that they are participat-

\footnotetext{
${ }^{1}$ Falk (2007) finds that gift-giving is a profitable device to raise charitable contributions.

${ }^{2}$ If workers know that they are participating in an experiment their behaviour may be affected, limiting the generalizeability of the experimental results.
} 
ing in an experiment; examples include Gneezy and List (2006) and Bellemare and Shearer (2009). This requires explaining the gift in a manner that is credible to the workers, yet exceptional. Repeating experiments may jeopardize the credibility of these explanations, contaminating the results. ${ }^{3}$ Finally, economic (or labour-market) conditions cannot be randomly assigned in typical field (or social) experiments (Heckman and Smith 1995). This renders impractical the experimental measurement of gift performance in different economic environments.

An alternative approach is to exploit the observed behaviour within a limited number of experiments to estimate structural parameters that govern worker responses to gifts. These parameters can then be used to predict the profitability of different gifts under different economic (and labour market) conditions, even those not observed within a particular experiment. Applying structural models to experimental data has been advocated by Heckman and Smith (1995) as a means of permitting generalization. It has been applied to social experiments by Todd and Wolpin (2006) and by Lise, Seitz and Smith (2005) and to firm-level field experiments by Shearer (2004) and Paarsch and Shearer (2008). We follow this approach, developing and estimating an economic model of gift giving within the tree-planting firm.

In our model, a worker's effort decision is governed by two key parameters: one measuring the curvature of the cost of effort function and another, a kindness parameter, measuring the worker's response to monetary gifts from the firm. Modelling worker utility as a function of kindness is in the spirit of Rabin's (1993) theoretical work on fairness and reciprocity. We show that optimal gift-giving/piece-rate contracts can be calculated from the knowledge of these parameters and an additional parameter, capturing general working conditions.

We identify our model through a series of field experiments conducted within the treeplanting firm. During the first experiment (which we call "the piece-rate experiment") the piece rate paid to workers was exogenously increased by between 20 and 28 percent.

\footnotetext{
${ }^{3}$ Randomizing gifts within a single experiment can create jealousies among workers within the firm and may be ruled out on principle by firm managers. In Bellemare and Shearer (2009), the firm insisted that the gift be the same to everybody.
} 
The recorded data, containing information on the number of trees each worker planted and the piece rate they received, identifies the curvature of the worker's cost of effort function. During the second experiment (which we denote "the gift experiment"), workers received a monetary gift of $\$ 80$ (independent of their productivity) from their employer, in addition to their regular piece rate. This represented a substantial amount of money to these workers, approximately $40 \%$ of average daily earnings. The recorded data, which contains information on the number of trees planted with and without the gift, identifies the worker's kindness parameter, conditional on the cost of effort.

Our results show that gifts do have a role to play within this firm. While the experimental gift did not generate a profitable response, other gifts would have been profitable, at least under certain economic conditions. Our analysis points to the importance of the substitutability of piece rates and gifts, and crowding out - under economic conditions which lead to low-powered incentives, gifts become more profitable. This is captured in our model by labour-market conditions which determine piece rates in the absence of gifts. Under slack labour-market conditions, market-clearing piece rates are lower, implying a greater role for gifts within the firm. Moreover, our results indicate that worker sensitivity to the firm's kindness is heterogeneous; approximately one-half of the workers in our sample exhibit no significant preferences for reciprocity.

Our policy analysis concentrates on three questions. First, we consider whether another base-wage gift would have generated a profitable response within the conducted experiment. Here, our results are negative - the explicit incentives provided by the observed piece rate (20 cents per tree) reduce the profitability of base-wage gifts. Second, we ask if a piece-rate gift would have been profitable. In this case we find that piece-rate gifts would increase firm profits, but only under labour-market conditions which lead to low piece rates in the absence of gifts. Piece-rate gifts are particularly profitable for workers who have strong reciprocal preferences - profit increases can attain $14 \%$ for certain workers among this group. Finally, we ask if more general (composite) gifts, including a base wage and a piece rate, would have been profitable. Here, we find that gifts would increase profits per worker by up to $10 \%$ on average, and by up to $17 \%$ for workers exhibiting strongly reciprocal preferences. In terms of composition: we find that profitable 
gifts should be provided by setting higher than market clearing piece-rates rather than a positive base wage. This is explained in our model by the fact that the workers in our sample respond more strongly to piece-rate gifts than to base wage gifts.

The rest of the paper is organized as follows. The next section describes the institutional setting of the tree-planting industry in British Columbia and the firm in which the experiment took place. In Section 3 we describe the experiments. Section 4 presents the economic model. In Section 5 we discuss identification. In Sections 6 and 7 we present the descriptive statistics and the estimation results. In Section 8 we present our policy analysis and in Section 9 we conclude.

\section{Tree Planting in British Columbia}

\subsection{The Industry}

Tree planting is a simple, yet physically exhausting, task. It involves digging a hole with a special shovel, placing a seedling in this hole, and then covering its roots with soil, ensuring that the tree is upright and that the roots are fully covered. The amount of effort required to perform the task depends on the terrain on which the planting is done and weather conditions. Flat plateaux are much easier to plant than steep mountain sides and hard, rocky soil is more difficult to plant than soft terrain.

Tracts of land that have recently been logged are allocated to tree-planting firms through a process of competitive bidding. These auctions typically take place in the autumn of the year preceding the planting season, which generally runs from early spring through to late summer. Planters are paid using piece-rate contracts. Under these contracts, planters are paid in proportion to their output. Generally, no explicit base wage or production standard exists, although firms are governed by minimum-wage laws. Output is measured as the number of trees planted per day.

\subsection{The Firm}

Our experiments were conducted within a medium sized tree-planting firm that employs approximately 70 planters per year. The planters represent a broad group of individuals, 
including returning seasonal workers and students working on their summer holidays. They range in age from 19 to 56.

This firm pays its planters piece rates; daily earnings for a planter are determined by the product of the piece rate and the number of trees the planter planted on that day. Blocks to be planted typically contain between 20 and 30 planter-days of work, with some lasting over 100 planter-days. For each block, the firm decides on a piece rate that applies to all planting done on the block. The piece rate for a particular block is set as a function of the labour-market conditions and the planting terrain on that block. Since planting conditions affect the number of trees that workers can plant, blocks for which average conditions are more difficult require higher piece rates to attract planters.

Contracts, comprising a number of blocks in the same geographic area, are planted by crews of workers under a supervisor. Each crew typically has from 10 to 20 planters. All workers planting on the same block receive the same piece rate; no matching of workers to planting conditions occurs. Typically, planters are assigned to plots within a block as they disembark from the ground transportation taking them to the planting site. They also have little contact with other workers during their work day. Thus, to a first approximation, planters were randomly assigned to plots. Identification of our structural model exploits the exogenous variation induced by two experiments conducted inside this firm.

\section{The Field Experiments}

\subsection{The Piece-Rate Experiment}

The piece-rate experiment took place on three separate blocks, over a three-month period in 2003. ${ }^{4}$ During the experiment, each homogeneous block was divided into two parts. One of these parts was then randomly chosen to be planted under the regular piece rate, the other to be planted under the treatment piece rate (equal to the regular piece rate plus five cents). The regular piece rates paid on these blocks were 18 cents and 23 cents, respectively. The treatment piece rates therefore represented an increase of between 21 and 27

\footnotetext{
${ }^{4}$ Data from this experiment were first analyzed in Paarsch and Shearer (2008). We refer the reader to that paper for a complete discussion of the experiment and the data.
} 
percent above the regular piece rate; 21 planters participated in the piece-rate experiment.

In order to avoid workers interpreting the experimental changes in the piece-rate as gifts from the firm, these changes were presented to the workers within the context of the normal daily operations of the firm. To this effect, the firm presented the treatment and control blocks as separate blocks, with separate piece rates. ${ }^{5}$ Note that this required spatial separation of the plots to be planted under each piece rate. As such, individual plots could not be randomly assigned to regular and treatment piece rates, but rather half of the block was randomly assigned to regular and half to treatment piece rates.

\subsection{The Gift Experiment}

The gift experiment ${ }^{6}$ took place on one homogeneous planting block which was planted over a seven-day period in June, 2006. This seven-day period was spread over two weeks. The first and second days of planting on the block took place on Thursday and Friday of the first week. The remaining 5 days of planting on the block took place from Monday to Friday of the following week. The piece rate paid to planters on this block was $\$ 0.20$ per tree. Eighteen planters were involved in the experiment, each planting between two and seven days on the experimental block. All eighteen planters were present for the second and third days of planting on the experimental block.

Upon arrival at the experimental block for the second day of planting, planters were informed that they would receive a lump-sum of $\$ 80$ for that day's work, in addition to the regular piece rate of twenty cents per tree. In order to avoid any effects of the experiment on participation, the $\$ 80$ was presented to the planters after they had departed from the base camp.

Workers in the gift experiment were unaware that they were participating in an experiment. This allowed us to formulate the money as a gift to the planters from the firm and

\footnotetext{
${ }^{5}$ A convincing explanation for the difference in piece rates was prepared invoking the fact that conditions on the treatment blocks had changed since the original bidding. This sometimes happens when the block has been unexpectedly prepared (cleared of debris) by the government. In practice, no explanation was needed as none of the planters questioned the higher piece rates.

${ }^{6}$ This discussion parallels that found in Bellemare and Shearer (2009) which analysed these data using an unrestricted econometric framework.
} 
to observe the worker's response to that gift in their natural work environment. To this end, planters were told by the firm manager that there was extra money in the contract since some of the previously-planted blocks had been expected to present access problems to the workers. This caused the firm to bid "walkin" compensation to the contract for those blocks. ${ }^{7}$ In the end, the access problems did not materialize and the compensation was not needed. In spite of this, the manager had decided to share the extra money with the planters. This represented a realistic explanation to the workers since access problems occur occasionally and "walkin-fees" are the typical solution of the firm when they occur. ${ }^{8}$

A second important feature of our design is that workers were told the gift was a onetime event that would not be repeated. This was reinforced by attaching the gift to an extremely rare occurrence, minimizing any repeated-game effects whereby the workers might respond in the hopes of earning future gifts (or surpluses); see, for example, Shapiro and Stiglitz (1984) or Macleod and Malcolmson, (1989). Access problems requiring walkin fees occur on approximately $2-3 \%$ of all planting blocks. The firm plants approximately 300 blocks in a given year and most workers are affected only once or twice per year. That in itself is a rare event. Even more exceptional is the fact that the originally observed access problems did not materialize - the government unexpectedly opened an access road. Firm managers affirmed that, while this does occur, (the government sometimes acts to open up areas to logging), it was an extremely rare event, occurring on perhaps $1 \%$ of the blocks for which walkin fees are bid. ${ }^{9}$

Finally, the manager was instructed to treat the day of the gift as a normal working day: planters worked the same number of hours as a regular workday and were monitored in the same way. What is more, the manager reported that nothing out of the ordinary (such as a truck breaking down or trees being delivered late) occurred on that day that would affect planting.

\footnotetext{
7“Walkin-fees” compensate planters for time spent walking into planting sites and are bid into contracts to plant sites that are difficult to access.

${ }^{8}$ None of the planters questioned this explanation.

${ }^{9}$ This suggests that the event will occur approximately once in every 3000 blocks planted, implying a worker would have to work, on average, 10 years in the firm to experience it.
} 


\section{Economic Model}

In this section, we present our model which can be used to analyse the profitability of different gift-giving contracts. The next section discusses the identification of the model using the exogenous variation in piece-rates and gifts provided by our field experiments.

\subsection{Technology}

The daily output of worker $i$ on block $j, Y_{i j}$, is a function of worker effort, $E_{i j}$ and a random production shock, $S_{i j}$. We specify

$$
Y_{i j}=E_{i j} S_{i j}
$$

where $S_{i j}$ is a positive random variable with

$$
S_{i j} \sim \operatorname{IID}\left(\mu_{j}, \sigma_{j}^{2}\right)
$$

\subsection{Utility}

Workers have utility functions given by

$$
U_{i}\left(W_{i j}, E_{i j}\right)=W_{i j}-C_{i}\left(E_{i j}\right)+\beta\left(Y_{i j}-Y_{i j}^{N G}\right) G_{i j}
$$

where $W_{i j}$ represents daily earnings and $C\left(E_{i j}\right)$ is the worker's cost of effort function and $\beta\left(Y_{i j}-Y_{i j}^{N G}\right) G_{i j}$ represents the kindness function, capturing how workers respond to gifts from the firm. ${ }^{10}$ Following the work of Rabin (1993) on fairness, (3) specifies that the worker receives utility from returning value to the firm (in terms of output $Y_{i j}$ ) above $Y_{i j}^{N G}$ (defined below in (5b)), the productivity level of the worker in the absence of gifts. The utility gained is proportional to the size of the gift $G_{i j}$ (or kindness) received from the firm (defined in (6)). We specify the cost of effort function as a power function

$$
C_{i}\left(E_{i j}\right)=\kappa_{i} \frac{\gamma}{\gamma+1} E_{i j}^{(\gamma+1) / \gamma}
$$

where, $\gamma$ is a curvature parameter and $\kappa_{i}$ allows for individual heterogeneity.

\footnotetext{
${ }^{10} \beta G$ represents the marginal utility of returning value to the firm. $\beta$, therefore, represents the marginal utility of returning value to the firm per dollar of gift received.
} 
We first develop our model under piece rates, in the absence of gifts. This is the typical compensation system of the firm. Later we extend the model to consider gifts. In developing our model, we closely follow the actual piece-rate setting policy of the firm, based on extensive interviews with firm managers.

\subsection{Timing}

The timing of events in our model is as follows:

- for a particular block $j$ to be planted, Nature chooses the pair $\left(\mu_{j}, \sigma_{j}^{2}\right)$, the parameters of the distribution of $S_{i j}$;

- the firm observes $\left(\mu_{j}, \sigma_{j}^{2}\right)$, and then chooses a contract $\omega_{j}$;

- the planter observes $\left(\mu_{j}, \sigma_{j}^{2}, \omega_{j}\right)$, and accepts or rejects the contract;

- if the planter accepts the contract, then he is randomly assigned to plant a particular plot on the block (ie, $s_{i j}$, a particular value of $S_{i j}$ is attributed to the planter);

- the planter observes $s_{i j}$, and chooses an effort level $E_{i j}$ producing output $Y_{i j}$;

- the firm observes $Y_{i j}$, and pays earnings $W_{i j}$.

To solve the model, we work backwards. First, we solve for the planter's optimal effort level conditional on a given piece rate and productivity shock. Then we solve for the firm's choice of the piece rate, taking the reaction of the planter as given. Note that, in order to induce the planter to accept the contract, the contract must satisfy the planter's participation constraint.

\subsection{Piece Rates}

Under piece-rate contracts all workers receive the same piece-rate $r_{j}$ on block $j: W_{i j}=r_{j} Y_{i j}$ and receive no gifts $\left(G_{i j}=0\right)$. Substituting (4) into (3) and using (1), optimal effort (for a 
specific realization of $s_{i j}$ ) and output are given by

$$
\begin{aligned}
E_{i j}^{N G} & =\left[\frac{r_{j} s_{i j}}{\kappa_{i}}\right]^{\gamma} \\
Y_{i j}^{N G} & =\left[\frac{r_{j}}{\kappa_{i}}\right]^{\gamma} s_{i j}^{\gamma+1}
\end{aligned}
$$

\subsection{Definition of Gifts}

Crucial to any analysis of gift giving is the definition of a gift. During our experiment the definition seems simple: it is the size of the bonus paid to workers. Yet, its simplicity is due to the fact that the piece rate is fixed. In settings where the firm can offer a gift by selecting both a piece rate and a base wage the definition must be more general. Here, we define the gift to be the gain in expected utility holding effort fixed at pre-gift levels. In particular, let the original piece-rate contract be defined by $r_{j}$ and the effort level $E_{i j}\left(r_{j}\right)$. Under a gift contract, denoted by a piece rate, $R_{j}$ and a base wage $B_{j}$, we define the gift to the worker as

$$
\begin{aligned}
G_{i j}\left(R_{j}, B_{j}, r_{j}\right) & =\boldsymbol{E}\left\{B_{j}+R_{j} E_{i j}\left(r_{j}\right) S_{i j}-C_{i}\left(E_{i j}\left(r_{j}\right)\right)-\left[r_{j} E_{i j}\left(r_{j}\right) S_{i j}-C_{i}\left(E_{i j}\left(r_{j}\right)\right)\right]\right\} \\
& =B_{j}+\left(R_{j}-r_{j}\right) r_{j}^{\gamma} A_{i j} .
\end{aligned}
$$

where $E$ represents the expectations operator and

$$
A_{i j} \equiv \frac{\boldsymbol{E}\left(S_{i j}^{\gamma+1}\right)}{\kappa_{i}^{\gamma}} .
$$

Note, this definition of gifts is empirically tractable - it depends on $\gamma$ and $A_{i j}$, both of which are identified given our data (see Section 5). ${ }^{11}$ Moreover, given (3), the gift is simply the gain in expected earnings at pre-gift effort levels. Notice, as well, when the piece rate is fixed at pre-gift levels $\left(R_{j}=r_{j}\right)$ (as it was during the gift experiment), the gift is equal to the base wage; ie, $G_{i j}=B_{j}$. Otherwise, (6) is very general, defining gifts in terms of contractual changes in both the piece rate and a base wage that raise expected utility.

\footnotetext{
${ }^{11}$ Alternatively, it would be possible to define gifts in (6) conditional on the shock $S_{i j}=s_{i j}$. This would not affect our parameter estimates given our experimental gift was given as a base wage $\left(G_{i j}=B_{j}\right.$ in (6)) and thus is independent of the way we treat $S_{i j}$. It would however complicate the policy analysis of optimal gift-giving contracts in section 8.3. See footnote 23 for a more detailed discussion.
} 
There is, however, a caveat: recent work suggests that the context in which contractual changes are explained to workers affects reciprocity. ${ }^{12}$ We therefore only consider changes in the contract to be gifts if they are explicitly explained to the workers as acts of kindness changes which are clearly in the short term interests of the firm or which are implemented without explanation are not considered to be gifts.

\subsection{Gifts and Reciprocity}

When workers receive a monetary gift from the firm, $G_{i j}>0$ and their response depends on their kindness parameter, $\beta$. Worker effort and output (given a realization of $s_{i j}$ ) are given by

$$
\begin{aligned}
E_{i j}^{G} & =\left[\frac{\left(R_{j}+\beta G_{i j}\right) s_{i j}}{\kappa_{i}}\right]^{\gamma} \\
Y_{i j}^{G} & =\left[\frac{R_{j}+\beta G_{i j}}{\kappa_{i}}\right]^{\gamma} s_{i j}^{(\gamma+1)}
\end{aligned}
$$

Note, under the original piece-rate contract, $R_{j}=r_{j}, B_{j}=0$ and hence $G_{i j}=0$. Then, (8a) and $(8 b)$ are equal to $(5 a)$ and $(5 b)$ respectively.

\subsection{Expected Utility}

In order for workers to accept a given contract, it must satisfy their participation constraint. Note, this places additional restrictions on the contract. The expected utility constraint takes account, not only the value of the gift, but the reaction of the worker to that gift (in terms of effort).

Substituting optimal effort, (5a) into (3) and taking expectations, worker $i$ 's expected utility in the absence of gifts is written

$$
\frac{r_{j}^{\gamma+1} A_{i j}}{(\gamma+1)}
$$

In the presence of gifts, expected utility is given by

$$
B_{j}+\frac{\left[R_{j}+\beta G_{i j}\right]^{(\gamma+1)} A_{i j}}{\gamma+1}-\beta G_{i j} r_{j}^{\gamma} A_{i j}
$$

\footnotetext{
${ }^{12}$ See Fehr, Goette and Zehnder, 2009, page 37.
} 


\subsection{Profits}

The firm's expected profit $\pi$ from worker $i$ on block $j$ under gift giving is given by

$$
\begin{aligned}
\boldsymbol{E}\left(\pi_{i j}^{G}\right) & =\left(P_{j}-R_{j}\right) \boldsymbol{E}\left(Y_{i j}^{G}\right)-B_{j} \\
& =\left(P_{j}-R_{j}\right)\left[R_{j}+\beta G_{i j}\left(R_{j}, B_{j}, r_{j}\right)\right]^{\gamma} A_{i j}-B_{j} .
\end{aligned}
$$

Notice that expected profits are a function of the structural parameters $\gamma, \beta$ as well as the parameter $A_{i j}$ capturing individual ability and planting conditions.

Profits can be calculated under piece-rate contracts (in the absence of gifts) by evaluating (11) at $R_{j}=r_{j}$ and $B_{j}=0$, giving

$$
\begin{aligned}
\boldsymbol{E}\left(\pi_{i j}^{N G}\right) & =\left(P_{j}-r_{j}\right) \boldsymbol{E}\left(Y_{i j}^{N G}\right) \\
& =\left(P_{j}-r_{j}\right) r_{j}^{\gamma} A_{i j} .
\end{aligned}
$$

\section{Identification and Estimation}

From (11) and (12), calculating profits on the experimental block requires identifying $\gamma, \beta$ and $A_{i j} \cdot{ }^{13}$ We exploit two sources of experimental data to identify these parameters: the piece-rate experiment and the gift experiment.

\subsection{The Piece-Rate Experiment}

The first source of identification is experimental variation in the piece rate, used to identify $\gamma$. During this experiment, conducted in 2003, the piece rate paid to planters was exoge-

\footnotetext{
${ }^{13}$ Generalizing to other blocks would require imposing more structure on the estimation problem. One possibility would be to impose that piece-rate contracts satisfy the participation constraint of the lowest-ability (or marginal) worker in the firm (denoted $h$ ), with productivity parameter $\kappa_{h}=\max \left\{\kappa_{1}, \kappa_{2}, \ldots, \kappa_{n}\right\}$. For example, let $\bar{u}$ denote the utility of worker $h$ from leaving the firm (his outside option). Under these circumstances, $A_{i j}$ can be written as

$$
A_{i j}=\left[\frac{\kappa_{h}}{\kappa_{i}}\right]^{\gamma} \frac{\bar{u}}{r_{j}^{\gamma+1}}
$$

a function of structural parameters and the piece rate paid on a particular block.
} 
nously increased by 5 cents, from a base of either 18 cents or 23 cents. Let $r^{T}$ and $r^{C}$ denote the treatment and control piece rates, respectively. Then, from (5b),

$$
\begin{aligned}
& \ln \left(Y_{i j}^{T}\right)=\gamma \ln \left(r_{j}^{T}\right)-\gamma \ln \left(\kappa_{i}\right)+(\gamma+1) \ln \left(S_{i j}\right) \\
& \ln \left(Y_{i j}^{C}\right)=\gamma \ln \left(r_{j}^{C}\right)-\gamma \ln \left(\kappa_{i}\right)+(\gamma+1) \ln \left(S_{i j}\right) .
\end{aligned}
$$

Let $J^{p r}$ denote the number of blocks in the piece-rate experiment, and $I^{p r}$ the number of planters. Furthermore, define $\left\{D b_{j}: j=1,2, \ldots, J^{p r}\right\}$ as dummy variables taking a value of 1 for block $j$, and 0 otherwise. Similarly, define $\left\{D I_{i}: i=1,2, \ldots, I^{p r}\right\}$ as dummy variables taking a value of 1 for planter $i$, and 0 otherwise. Then, combining (14a) and (14b) gives

$$
\ln \left(Y_{i j}\right)=a_{0}+\sum_{i=2}^{I^{p r}} a_{1 i} D I_{i}+\sum_{j=2}^{p^{p r}} a_{2 j} D b_{j}+\gamma\left(\ln \left(r_{j}^{T}\right)-\ln \left(r_{j}^{C}\right)\right) D T_{i j}+\epsilon_{i j}
$$

where

$$
\begin{aligned}
a_{0} & =-\gamma \ln \left(\kappa_{1}\right)+\gamma \ln \left(r_{1}^{C}\right)+(\gamma+1) \boldsymbol{E}\left(\ln S_{i 1}\right) \\
a_{1 i} & =\gamma\left(\ln \left(\kappa_{1}\right)-\ln \left(\kappa_{i}\right)\right) \\
a_{2 j} & =(\gamma+1)\left[\boldsymbol{E}\left(\ln S_{i j}\right)-\boldsymbol{E}\left(\ln S_{i 1}\right)\right]+\gamma\left(\ln \left(r_{j}^{C}\right)-\ln \left(r_{1}^{C}\right)\right) \\
\epsilon_{i j} & =(\gamma+1)\left[\ln S_{i j}-\boldsymbol{E}\left(\ln S_{i j}\right)\right]
\end{aligned}
$$

and

$$
D T_{i j}= \begin{cases}1 & \text { if paid treatment piece rate on block } j, \\ 0 & \text { if paid control piece rate on block } j\end{cases}
$$

The exogenous variation in the piece rate implies that the expected value of $\epsilon_{i j}$ is equal to zero, conditional on the included regressors. Hence, the model in (15) identifies $\gamma .{ }^{14}$

\subsection{The Gift Experiment}

The second source of identification comes from the gift-giving experiment, used here to identify $\beta$ and $A_{i j}$ for the block on which the gift-giving experiment took place. From (5b) and ( $8 \mathrm{~b})$, and using the fact that $G_{i j}=B_{j}$ during the experiment, we can write

$$
\begin{aligned}
\ln \left(Y_{i j}^{G}\right) & =\gamma \ln \left[r_{j}+\beta B_{j}\right]-\gamma \ln \left(\kappa_{i}\right)+(\gamma+1) \ln \left(S_{i j}\right) \\
\ln \left(Y_{i j}^{N G}\right) & =\gamma \ln \left(r_{j}\right)-\gamma \ln \kappa_{i}+(\gamma+1) \ln \left(S_{i j}\right)
\end{aligned}
$$

\footnotetext{
${ }^{14}$ Recall, we do not interpret the piece-rate experiment in terms of gifts, since the increase piece rate was not presented to the workers as a gift; see footnote 5 and section 4.5 .
} 
Combining (16a) and (16b) gives

$$
\ln Y_{i j}^{\star}=\gamma\left[\ln \left(r_{j}+\beta B_{j}\right)-\ln \left(r_{j}\right)\right] D G I F T_{i j}-\gamma \ln \left(\kappa_{i}\right)+(\gamma+1) \boldsymbol{E}\left(\ln \left(S_{i j}\right)\right)+v_{i j}
$$

where

$$
\begin{aligned}
\ln \left(Y_{i j}^{\star}\right) & =\ln \left(Y_{i j}\right)-\gamma \ln \left(r_{j}\right) \\
v_{i j} & =(\gamma+1)\left[\ln \left(S_{i j}\right)-E\left(\ln \left(S_{i j}\right)\right)\right]
\end{aligned}
$$

and

$$
\operatorname{DGIFT}_{i j}= \begin{cases}1 & \text { if receive gift, } \\ 0 & \text { else }\end{cases}
$$

The model (17) includes individual-specific effects which are needed to recover an estimate of $A_{i j}$. In order to gain information over individual-specific heterogeneity we supplement the experimental data with payroll data, collected on the experimental participants, planting on blocks near to the experimental block. We specify $(\gamma+1) \boldsymbol{E}\left(\ln S_{i j}\right)$ as a blockspecific effect, $D b_{j}$, and $\gamma \ln \kappa_{i}$ as an individual-specific term, $D I_{i}$. The estimating equation is

$$
\ln \left(Y_{i j}^{\star}\right)=b_{0}+\sum_{i=2}^{I^{g}} b_{1 i} D I_{i}+\gamma\left[\ln \left(r_{j}+\beta B_{j}\right)-\ln r_{j}\right] D G I F T_{i j}+\sum_{j=2}^{J^{g}} b_{2 j} D b_{j}+v_{i j}
$$

where $I^{g}$ denotes the number of planters in the gift experiment and $J^{g}$ the number of blocks. The exogenous variation in the gift implies that the expected value of $v_{i j}$ is equal to zero, conditional on the included regressors. Hence, conditional on $\gamma$, the model in (18) identifies $\beta$.

Notice as well that

$$
S_{i j}^{\gamma+1}=\exp ^{(\gamma+1) \ln \left(S_{i j}\right)}=\exp ^{(\gamma+1) E\left(\ln \left(S_{i j}\right)\right)+v_{i j}}
$$

giving

$$
\boldsymbol{E}\left(S_{i j}^{\gamma+1}\right)=\exp ^{(\gamma+1) \boldsymbol{E}\left(\ln \left(S_{i j}\right)\right)} \boldsymbol{E}\left(\exp ^{v_{i j}}\right)
$$

Hence,

$$
\begin{aligned}
A_{i j} & =\frac{\boldsymbol{E}\left(S_{i j}^{\gamma+1}\right)}{\kappa_{i}^{\gamma}} \\
& =\frac{\exp ^{(\gamma+1) E\left(\ln \left(S_{i j}\right)\right)}}{\kappa_{i}^{\gamma}} \boldsymbol{E}\left(\exp ^{v_{i j}}\right) \\
& =\exp ^{b_{0}+\sum_{i=2}^{I^{g}} b_{1 i} D I_{i}+\sum_{j=2}^{j^{g}} b_{2 j} D b_{j}} \times \boldsymbol{E}\left(\exp ^{v_{i j}}\right)
\end{aligned}
$$


which we estimate by

$$
\widehat{A}_{i j}=\exp ^{\hat{b}_{0}+\sum_{i=2}^{I g} \hat{b}_{1 i} D I_{i}+\sum_{j=2}^{I^{g}} \hat{b}_{2 j} D b_{j}} \times \sum_{i} \frac{\exp ^{\hat{\vartheta}_{i j}}}{n_{j}}
$$

where $\hat{v}_{i j}$ denote the residuals from (18).

\subsection{Estimation of model parameters}

We estimate our model parameters using a two-step, non-linear least squares estimator. In the first step, we estimate $\gamma$ from (15) using the experimental variation in the piece rate. We then estimate $\beta$ and $A_{i j}$, conditional on $\gamma$, from (18) using the gift experiment data. To calculate the critical value for the t-statistic on $\beta$, taking account of its dependence on $\gamma$, we used the bootstrap technique. ${ }^{15}$

\section{Descriptive statistics}

Table 1 presents the summary statistics of the piece-rate experiment averaged over all planters in both treatment and control conditions. The average daily number of trees planted under the control conditions is 888.95 , with a relatively high standard deviation. Under the treatment conditions, the average number of trees planted climbs to 1012.39. This reflects a $13.9 \%$ increase in planter productivity relative to the control conditions, a change consistent with the higher piece-rates paid in the treatment conditions. ${ }^{16}$

Table 2 presents the summary statistics of the gift experiment averaged over all planters in both treatment and control conditions. Under the control conditions, planters received

\footnotetext{
${ }^{15}$ The bootstrap proceeded as follows. First, we generated 999 bootstrap estimates of $\gamma$ from the piece-rate experiment. For each estimated value of $\gamma$, denoted $\hat{\gamma}_{b}^{\star}$, we then bootstrapped a sample from the gift-giving experiment, estimated $\hat{\beta}_{b}^{\star}$ and calculated

$$
t_{b}^{\star}=\frac{\hat{\beta}_{b}^{\star}-\hat{\beta}}{s_{\hat{\beta}_{b}^{\star}}} .
$$

This gives 999 values of the bootstrapped test statistic which we order from smallest to largest. The upper-tail $(5 \%)$ critical value for the test statistic is the 975th value in the ordered series of $t_{b}^{\star}$; see, for example, Cameron and Trivedi (2005), page 363.

${ }^{16}$ This pattern holds conditionally as well - productivity is higher under the treatment piece rate for each block; see Paarsch and Shearer (2008), Table 2.
} 
$0.20 \$$ per tree planted, yielding an average daily productivity of 1063.64 trees planted. When the gift is handed out (treatment conditions), the average daily number of trees planted is 1153.06 , an $8.4 \%$ increase in planter productivity relative to planting without a gift.

Table 3 presents the summary statistics for the gift-experiment planters, planting on both experimental and non-experimental blocks. The average number of trees planted per day is equal to 988 trees. This is lower than on the experimental block and reflects the fact that the experiment was conducted on somewhat easier conditions than average. This is also reflected in the fact that the average piece rate is $\$ 0.23$, higher than that paid on the experimental block. We note, however, that average earnings are very similar - \$220 per day when averaged over all blocks and $\$ 230$ on the experimental block.

\section{Estimation Results}

The estimate of $\gamma$ is equal to $0.39 .{ }^{17}$ A statistical test of the null hypothesis that $\gamma$ is equal to zero is rejected at all levels of statistical significance - the $p$-value is essentially equal to zero. $^{18}$

\subsection{Homogeneous Response}

The estimate of $\beta$ is equal to .00071 and is statistically significant at the $5 \%$ level - the $t$ statistic for $\beta$ is equal to 1.77 , while the (bootstrapped) critical value for the t-statistic is equal to 1.67. The worker's marginal utility of reciprocating (returning an additional tree to the firm in response to the gift) is given by $\beta B_{j} .{ }^{19}$ Given $B_{j}=80 \$$, the marginal utility is estimated to be $0.057 \$$.

\footnotetext{
${ }^{17}$ Paarsch and Shearer (2008) also estimate a value of $\gamma$ of 0.39 using the same data.

${ }^{18}$ Controlling for weather in (15) had no effect on the results.

${ }^{19}$ Recall that $G_{i j}=B_{j} \forall i$ during the experiment.
} 


\subsection{Heterogeneous Response}

To allow for heterogeneity in response to the gift we allow $\beta$ to be a function of observable individual characteristics: age and tenure. In particular, we specify

$$
\beta_{i}=\beta_{0}+\beta_{1} \times \text { tenure }_{i}+\beta_{2} \times \text { age }_{i}+\beta_{3} \times \text { age }_{i} \times \text { tenure }_{i} .
$$

The estimated response function is 20

$$
\begin{gathered}
\hat{\beta}_{i}=0.00042+0.00043 \times \text { tenure }_{i}+(2.72 e-6) \times \text { age }_{i}-(9.79 e-6) \times \text { age }_{i} \times \text { tenure }_{i} \\
(0.71) \\
(5.44)^{\star \star \star}
\end{gathered}
$$

Here, the estimated t-statistics are given in parentheses; $\star \star \star$ denotes statistical significance at the $1 \%$ level. ${ }^{21}$ The estimates suggest that reciprocity is associated with a longer tenure within the firm, yet this effect is diminished with age. The positive effect of tenure on reciprocity is consistent with Akerlof's (1982) notion that the benefits from gift giving increases with time spent in the firm; see, Bellemare and Shearer (2009) for a more complete discussion.

The estimated individual responses to the gift along with the estimated values of $A_{i j}$ (for the experimental block) are presented in Table 4. In general, the estimates show considerable heterogeneity in response. The small number of treatment observations affects the precision with which we can measure individual responses. Nevertheless, these responses are statistically significant at the $10 \%$ level for 10 planters, at the $5 \%$ level for 8 planters and at the $1 \%$ level for 2 planters. While the effect is estimated to be negative for one planter, it is not statistically significant. The $A_{i j}$ parameters are all very precisely estimated. This is perhaps not surprising since this parameter represents average productivity of individual $i$ on the experimental block. Notice as well that from (7), $E\left(S_{i j}^{\gamma+1}\right)$ is the same across planters on block $j$, implying higher values of $A_{i j}$ represent more productive work-

\footnotetext{
${ }^{20}$ The bootstrapped $1 \%$ critical values for a two-sided alternative are equal to $3.10\left(\beta_{0}\right), 4.06\left(\beta_{1}\right), 2.94\left(\beta_{2}\right)$ and $-3.88\left(\beta_{3}\right)$. The bootstrapped $5 \%$ critical values are equal to $2.45\left(\beta_{0}\right), 2.90\left(\beta_{1}\right), 1.98\left(\beta_{2}\right)$ and $-2.85\left(\beta_{3}\right)$.

${ }^{21}$ We controlled for daily temperature, rainfall and day of the week in the estimation of (18). The estimates of these parameters are available from the authors on request.
} 
ers (individuals with lower values of $\kappa_{i}$ ). The estimates show substantial heterogeneity in planter productivity.

Table 5 provides further insight into the heterogeneity of worker responses to gifts and their characteristics. The second column replicates the estimated value of $\beta_{i}$ from Table 4. Column 3 presents the estimated marginal utility to the worker of returning value to the firm $\left(\beta_{i} \times B_{j}\right)$ after receiving the experimental gift. These values are measured in dollars per tree planted; they range from 1 to 19 cents per tree planted with an average of 6 cents over the sample. What is more, one-half of the sample displays very weak reciprocal preferences, earning marginal utility from reciprocating the gift of less than 5 cents per tree planted. Columns 4 and 5 give the estimated response to the experimental gift in real and monetary terms. ${ }^{22}$ Again, these numbers reflect the heterogeneity in reciprocity among these planters: 7 out of the 18 planters returned value of less than $\$ 10$ to the firm in response to the $\$ 80$ gift, while 3 planters returned value greater than $\$ 35$; the maximum return to the firm was $\$ 56.80$. The high proportion of planters with weak reciprocal preferences will play an important role in the results of our policy analysis.

\section{Policy Analysis}

The firm received 35 cents for each tree planted on this contract and paid a piece rate of 20 cents to its workers, giving a net revenue of 15 cents per tree. The workers responded to the firm's gift with an increase of output in the order of 117 trees. Hence the 80 dollar gift generated only 17 dollars of revenue - the exchange of gifts was not profitable for the firm. However, it is important to bear in mind that the experimental gift was chosen by economists, not the firm. Other gifts may well have generated profitable responses. To investigate this we use our estimated parameters (allowing for heterogeneous response) to calculate the profits of alternative gift contracts. Throughout this section, $\bar{r}_{j}$ represents the standard piece rate paid to all planters on the experimental block (denoted $j$ ) during the gift experiment.

\footnotetext{
${ }^{22}$ The total response can differ for two planters with the same value of $\beta \times B_{j}$ since total response also depends on $A_{i j}$, see (8b).
} 
We consider gifts for which the firm must pay the same piece rate and the same base wage to all planters planting on the same block. This corresponds to current firm practice and avoids introducing extra contracting costs into the counterfactual analysis. Notice, however that homogeneous contracts does not imply homogeneous gifts - the size of the gift to any planter will generally depend on that planter's ability (see (6)).

A necessary condition for gifts to be profitable is for the profit-maximizing gift to increase profits vis-à-vis profits in their absence. We therefore measure the economic relevance of gifts by comparing profits earned under the profit-maximizing gift to profits earned under piece-rates. We consider a number of cases: base-wage gifts, piece-rate gifts and composite gifts (comprising both piece rates and base wages). Each is nested within the following program: the firm chooses $\left(R_{j}, B_{j}\right)$ to maximize ${ }^{23}$

$$
\max _{B_{j}, R_{j}} \sum_{i=1}^{I^{g}}\left(P_{j}-R_{j}\right)\left[R_{j}+\beta_{i} G_{i j}\left(R_{j}, B_{j}, \bar{r}_{j}\right)\right]^{\gamma} A_{i j}-B_{j}
$$

subject to:

1. the participation constraint

$$
B_{j}+\left[R_{j}+\beta_{i} G_{i j}\left(R_{j}, B_{j}, \bar{r}_{j}\right)\right]^{(\gamma+1)} \frac{A_{i j}}{(\gamma+1)} \geq \beta_{i} G_{i j} \bar{r}_{j}^{\gamma} A_{i j}+\frac{\bar{r}_{j}^{\gamma+1} A_{i j}}{(\gamma+1)}
$$

holds for each worker

2. gifts are determined by (6).

The participation constraint insures that workers are not worse off with a gift than without a gift, taking into account their response to the contract.

\footnotetext{
${ }^{23}$ An alternative discussed in section 4.5 is to define the gift conditional on the shock $s_{i j}$ which implies that
} $G_{i j}$ would depend on the realization $s_{i j}$. The expected profit from worker $i$ would then be given by

$$
\boldsymbol{E}\left(\pi_{i j}^{G} \mid R_{j}, B_{j}, r_{j}\right)=\int\left(P_{j}-R_{j}\right)\left[\frac{R_{j}+\beta G_{i j}\left(R_{j}, B_{j}, r_{j}, s_{i j}\right)}{\kappa_{i}}\right]^{\gamma} s_{i j}^{(\gamma+1)} f\left(s_{i j}\right) d s_{i j}-B_{j}
$$

Given the dependence of $G_{i j}$ on $s_{i j}$, identification of the expected profit requires identifying the distribution of $S_{i j}$ and the distribution of $k_{i}$. This would require possibly different data and/or additional model assumptions. 


\subsection{Profitable Base-Wage Gifts}

We first considered whether another experimental base-wage, $B_{j}$, provided as a gift on the same block, at the same piece rate and to the same planters, would have been profitable for the firm. In this case, we evaluated (22) at the estimated parameter values, subject to (23) and (6), imposing that $R_{j}=\bar{r}_{j}=0.20 .{ }^{24}$ We found that profit maximizing base-wage gifts were equal to zero. This suggests that no experimental base-wage gift would have generated a profitable response from the workers on the experimental block within the current labour market despite the fact that workers respond significantly to the gift.

A closer look at the effort function (8a) is revealing in considering these results. Since output is measurable (and contractible) gifts and piece rates are substitutes. Furthermore, because the piece-rate incentives are strong and workers' response to the gift is relatively small (the average $\hat{\beta}_{i}=.0009$ ) the profitability of a gift is attenuated at the observed piece rate.

\subsection{Profitable Piece-Rate Gifts}

Next we considered the profitability of piece-rate gifts. Recall, that these gifts are increases in the piece rate above market clearing levels, $\bar{r}_{j}$. In this case, we evaluated (22) at the estimated parameter values, subject to (23) and (6) while imposing that $B_{j}=0 .{ }^{25}$ Here, as in the case of base-wage gifts, we found the profit maximizing gift to be equal to zero, suggesting there is no role for piece-rate gifts on the experimental block within the current labour market.

\footnotetext{
${ }^{24}$ In practice, we evaluated a more specific problem in this case - allowing the firm to choose individualspecific base-wage gifts. Since this gives the firm finer strategy space, profits will be higher than if one base wage is given to each worker. Hence a finding of no profitable individual-specific base-wage gifts is stronger than finding no profitable homogeneous base-wage gift.

${ }^{25}$ We performed a numerical grid search to find the profit-maximizing solution, considering values of $R_{j} \in$ $\left[0, P_{j}\right]$ where, recall, $P_{j}$ is the price the firm receives per tree planted (equal to 0.35 in this case).
} 


\subsection{Profitable Composite Gifts}

Next, we considered composite gifts, allowing the firm to select both a piece rate and a base wage to generate gifts to the workers. One might expect profits to be higher in this situation since the firm now has two instruments to generate gifts. To proceed, we calculated the contract that maximizes (22) subject to (23) and (6). ${ }^{26}$

Here, we found that gifts were positive, although very small. The average gift was equal to $\$ 1.61$, while the minimum gift was zero and the maximum gift was $\$ 2.94$. Surprisingly, the gifts were comprised of a negative base wage $(-\$ 2.56)$ and a small increase in the piece rate ( $\$ 0.204$ versus $\$ 0.20$ ). The negative base wage may seem to contradict popular notions of gifts, giving an abstract element to composite gifts. Recall, however, that the gift is defined by the increase in expected utility (earnings) given pre-gift effort levels. This is assured by the increase in the piece rate. Overall these gifts have a negligible effect on firm profits in this context (less than one-half of 1\%), suggesting that (even composite) gifts have little role to play within the firm in the current context.

\subsection{Different Labour Markets}

Some authors have suggested that gifts are most useful in the presence of low-powered explicit incentives. ${ }^{27}$ In the tree-planting industry, the level of the piece rate (for a given set of planting conditions) is determined by the labour market; see section 2.2. To consider how gifts would perform in the presence of low-powered incentives, we constructed counterfactuals measuring the profitability of gifts under slack labour-market conditions - conditions in which the firm can lower piece rates on the experimental block and still retain all of its workforce. We hold the output price, worker ability and planting conditions constant.

Calculating profits under different labour-market conditions requires that we extend our model to capture how piece rates are determined; this requires additional assumptions.

\footnotetext{
${ }^{26}$ We performed a numerical grid search to find the profit-maximizing solution, considering values of $R_{j} \in$ $\left[0, P_{j}\right]$ and $B_{j} \in[-50,50]$.

${ }^{27}$ This can be due to crowding out (Fehr and Gachter, 2002) or due to multitasking problems rendering high-powered incentives ineffective (Fehr and Falk, 2002).
} 
We assume that, in the absence of gifts, the firm chooses the piece rate to maximize profits, subject to the participation constraints of the workers. Since workers are heterogeneous in terms of ability $\left(\kappa_{i}\right)$, we assume that the piece rate must satisfy the participation constraint of the marginal worker in the firm - that worker with the highest cost of effort (lowest ability), denoted $\kappa_{h} \cdot{ }^{28}$ This ensures that the all workers are willing to participate on every terrain planted. The firm's problem, for a given planting block, is then given by

$$
\begin{aligned}
\max _{r_{j}} \sum_{i=1}^{I^{g}} \boldsymbol{E}\left(\pi_{i j}^{N G}\right) & =\sum_{i=1}^{I^{g}}\left(P_{j}-r_{j}\right) \boldsymbol{E}\left(Y_{i j}^{N G}\right) \\
& =\sum_{i=1}^{I^{g}}\left(P_{j}-r_{j}\right) r_{j}^{\gamma} A_{i j} .
\end{aligned}
$$

subject to:

$$
\frac{r_{j}^{\gamma+1} A_{h j}}{(\gamma+1)} \geq \bar{u} .
$$

The solution to this problem is given by

$$
\tilde{\mathbf{r}}_{j}=\max \left\{\frac{\gamma}{\gamma+1} P_{j}, \bar{r}_{j}\right\}
$$

where

$$
\bar{r}_{j}=\left[(\gamma+1) \bar{u} A_{h, j}^{-1}\right]^{\frac{1}{(\gamma+1)}}
$$

the piece rate that solves the marginal worker's participation constraint.

The effect of the labour market operates through $\bar{u}$, changing the value of the worker's outside alternative. Hence, holding conditions and ability $\left(A_{h j}\right)$ constant, a decrease in the value of $\bar{u}$ decreases the piece rate $\bar{r}_{j}$ that guarantees the participation of the workers. In all cases, we consider values of $\bar{r}_{j} \in\left(0.01, P_{j}\right)$.

Profit maximization censors the piece rate at $\gamma /(\gamma+1) P_{j}$, that rate at which the marginal benefit of effort to the firm equals the marginal cost (the increase in earnings paid). Hence, while the firm could set a piece-rate lower than $\gamma /(\gamma+1) P_{j}$ when labor market conditions deteriorate sufficiently, the incentive incorporated in such rates is too low. As a result, the firm maintains the piece-rate at the profit maximizing level $\gamma /(\gamma+1) P_{j}$ in this range of labor market conditions. Given $P_{j}$ equals $\$ 0.35$ in our data, the censored value of the piece

\footnotetext{
${ }^{28}$ Our model follows Shearer (2004) and is based on extensive discussions with firm managers.
} 
rate is 0.1. Note, as well, since $\tilde{\mathbf{r}}$ now represents the piece rate that the firm would pay on this block under the prevailing labour-market conditions, we now define the piece-rate gift relative to $\tilde{\mathbf{r}}_{j}$.

\section{Base-Wage Gifts}

To investigate the profitability of base-wage gifts, we calculated the expected profits (based on (22)) for different values of $B_{j} \in[0,100]$, holding $R_{j}$ fixed at $\tilde{\mathbf{r}}_{j} \in\left[0, P_{j}\right]$. We find that there exists no value of $B_{j}$ such that the firm profits increase relative to the benchmark profit maximizing level in the absence of gifts. This is true for all values of $\tilde{\mathbf{r}}_{j}$ considered. Hence, base-wage gifts would never be used in equilibrium. This suggests that base-wage gifts have little role to play in this firm, even under labour-market conditions leading to low-powered incentives.

\subsubsection{Piece-Rate Gifts}

To investigate the profitability of piece-rate gifts we calculated the expected profits (based on (22)) for different values of $R_{j} \in\left[0, P_{j}\right]$, holding $B_{j}$ fixed at zero. We then computed the overall profit change (averaging over all workers) relative to benchmark profits; that is profits without gifts (based on (24) and (25)). We also computed the profit change relative to benchmark profits for each worker. The latter was done in recognition of the fact that workers have various predispositions to reciprocate to a gift from the firm, as revealed by the heterogenous estimates of $\beta_{i}$ in Table 4 .

The results are presented graphically in Figure 1 . Note, the vertical line at $\bar{r}_{j}=.1$ divides the figure into two regions: $\bar{r}_{j}>\gamma /(\gamma+1) P_{j}$ and $\bar{r}_{j}<=\gamma /(\gamma+1) P_{j}$. Consider first the region $\bar{r}_{j}>\gamma /(\gamma+1) P_{j}$. Recall, in this region, the participation constraint binds and hence the non-gift piece rate is determined by labour-market conditions. Here we found an economic role for gifts, particularly in the range $\bar{r}_{j}<0.15$. Profits from gift giving increase modestly in the range $0.1<\bar{r}_{j}<=0.15$, reaching their peak at $\bar{r}_{j}=0.1$ and remaining constant for all labour market conditions in the range $\bar{r}_{j}<=0.10$. Over this range a piece-rate gift would increase overall firm profits, vis-à-vis the regular piece-rate contract, by $3 \%$. However, there is substantial heterogeneity in the relative profitability of 
the gift across workers - we find that the maximal increase in per-worker profits relative to the benchmark is close to $15 \%$.

More information on the heterogeneity of profits is given in Figure 2. Here we present different percentiles from the distribution of the percent increase in profits across workers, for different values of $\bar{r}_{j}$. As in Table 5 we see evidence of considerable heterogeneity across workers. The percent increase in profits from a piece-rate gift is over $6 \%$ for 20 percent of the workers when $\bar{r}_{j} \leq 0.1{ }^{29}$ Yet, it is less than $2 \%$ for at least one-half of the workers in the firm. In fact, it is negative for 3 planters - those with the lowest values of $\beta_{i}$. This is due to the fact that when $\beta_{i}=0$, the effort and profit functions collapse to the piece-rate effort and profit functions. Any increase in the piece rate above the profit-maximizing level $\tilde{\mathbf{r}}_{j}$ under such circumstances necessarily decreases profits for those workers.

Figure 3 presents the average and maximal gifts of workers across the different labour market conditions. Here, we find that for $\bar{r}_{j} \leq 0.10$ the average gift is $\$ 21$ while the maximum gift is $\$ 28$. Average and maximal gifts progressively decline to zero as $\bar{r}_{j}$ approaches 0.15. Figure 4 presents the relative importance of gifts (measured as the gift as a proportion of expected earnings in the absence of gifts). ${ }^{30}$ Here we see that gifts increase in relative importance as labour-market conditions worsen, attaining $27 \%$ of expected piece-rate earnings for $\bar{r}_{j}<0.10$. $^{31}$

The increase in the profitability of gift-giving as labour market alternatives deteriorate is directly related to the associated decrease of incentives. Slack labor market conditions allow the firm to reduce the piece-rate paid to workers and still satisfy the participation constraints of workers. In doing so, the marginal cost (in terms of effort) of responding to the gift is also reduced. As a result crowding out diminishes - the marginal effect of increasing the gift on average worker productivity increases. ${ }^{32}$

\footnotetext{
29 The workers for whom gifts are the most profitable are those who have worked at the firm for a long period of time yet remain relatively young; those for whom the percent increase in profits is above $6 \%$ are planters 4,6, 13 and 18, all of whom are less than 40 years old and have tenure of 5 years or more (see Table 5).

${ }^{30}$ The relative importance of gifts is constant across workers for piece-rate gifts: Expected earnings in the absence of gifts are given by $\bar{r}_{j}^{\gamma+1} A_{i j}$. It then follows from (6) that the relative importance of individual is gift is $\left(R_{j}-\bar{r}_{j}\right) / \bar{r}_{j}$.

${ }^{31}$ Average earnings would be $\$ 80.00$ in this case, reduced from $\$ 195$ when the piece rate is 0.20 .

${ }^{32}$ This can be illustrated using the model of Section 4 . It follows from (8b) that the marginal effect of increas-
} 


\subsubsection{Composite Gifts}

Finally, we considered composite gifts in different labour markets, allowing the firm to select both a piece rate and a base wage to generate gifts to the workers. To proceed, we calculated the contract that maximizes (22) subject to (23), for different values of $\bar{r}_{j} \in$ $(0.01,0.35)$. The results, presented graphically in Figures 5 through 10 , suggest there is a potentially important role for composite gifts within this firm under slack labour-market conditions. Again, the vertical line at $\bar{r}_{j}=.1$ divides the graphs into two regions: $\bar{r}_{j}>$ $\gamma /(\gamma+1) P_{j}$ and $\bar{r}_{j}<=\gamma /(\gamma+1) P_{j}$. Figure 5 shows that for the region $\bar{r}>\gamma /(\gamma+1) P_{j}$ the firm could increase overall profits by up to $10 \%$ by introducing composite gifts.

The distribution of profit increases is presented in Figure 6. Again, there is considerable heterogeneity in the profitability of the gift across workers, although composite gifts are generally more profitable than piece-rate gifts. We find that the maximal profit increase, for a given worker, is $17 \%$ in the region $\bar{r}_{j}<=\gamma /(\gamma+1) P_{j}$. The median profit increase is $11.1 \%$, close to the average increase of $10.4 \%$. Notice, even workers in the 20th percentile of the distribution will provide profits over $8 \%$ under composite gifts.

Figure 7 shows the monetary size of the gifts. Gifts would be positive for $0.1<\bar{r}_{j}<$ 0.20 , with average gifts up to $\$ 20$ and a maximum gift of up to $\$ 37.50$. Average gifts vary between $\$ 20$ and $\$ 21.50$ while the maximum gift varies between $\$ 28$ and $\$ 49$. The importance of gifts decreases as we approach the observed piece rate, yet the maximum gift is still above $\$ 10$ at a piece rate of $\$ 0.18$. Figure 8 shows the relative importance of the average and maximum gifts, again measured as the gift as a proportion of expected earnings in the absence of gifts. As in Figure 4, gifts increase in importance as labour-market conditions worsen with the average gift attaining $23 \%$ of average expected earnings for $\bar{r}_{j}<=0.10 \$$; the maximum proportion is over 0.3 .

Figures 9 and 10 show the composition of the gift. Again, we find that the composite ing the gift $G_{i j}$ on average worker productivity is given by

$$
\frac{\partial^{2} E\left(Y_{i j}^{G}\right)}{\partial R_{i j} \partial G_{i j}}=(\gamma-1) \gamma \beta_{i}\left[\frac{R_{i j}+\beta G_{i j}}{\kappa_{i}}\right]^{\gamma-2} \boldsymbol{E}\left(s_{i j}^{(\gamma+1)}\right)
$$

This cross partial derivative is negative when evaluated at the estimated parameter values $\left(\hat{\gamma}=0.39, \hat{\beta}_{i}>0\right.$.). This indicates that all workers respond more to a gift when incentives are lower. 
gift takes an unexpected form: an increase in the piece-rate offset by a negative base-wage. These gifts allow the firm to increase profits even for workers with $\beta_{i}=0 .{ }^{33}$ In effect, a gift in the form of a higher piece rate generates effort on two levels: first, through the increase in the marginal return to effort; and second, through the reciprocal response to the gift. The negative base wage allows the firm to claw-back some of the excess rents that the high-incentive piece rate generates.

\section{Discussion and Conclusions}

This paper adds to the empirical literature on gift giving, concentrating on the profitability of gifts within the firm. We have used field experiments to measure worker responses to gifts, identifying structural parameters which permit the generalization of results beyond the experimental setting.

Our results suggest that gifts do have a role to play in this firm. While the experimental gift was not profitable, other gifts would have been. We estimate that firm profits for a given worker would increase by up to 17 percent, vis-à-vis a piece-rate contract, by the introduction of a profit maximizing gift. However, only one-half of the workers in this firm are predicted to reciprocate to a gift from their employer by increasing their effort level. This reduces the overall profits the firm can attain through gift giving - average profits increase $10 \%$.

It is notable that gifts have an economic impact within a firm where output is measurable. The principal of reciprocity states that workers will respond to gifts by returning value to the firm. Yet, if measurable output is valuable (as in tree planting), then piece rates and gifts are close substitutes and their use is determined by relative cost (or relative worker reaction to incentives). In our case, worker response to piece rates is relatively high; hence piece rates limit the effect of gifts during the experiment. In situations where the market clearing piece rate is low however (due to labour-market conditions in our model), then the relative value of gifts increases. In other industries measurable output

\footnotetext{
${ }^{33}$ Workers for whom $\beta_{i}=0$ will still participate in such contracts as long as $B_{j}+\left(R_{j}^{(\gamma+1)}-\bar{r}_{j}^{(\gamma+1)}\right) A_{i j} /(\gamma+$ $1) \geq 0$. The firm increases profits on such individuals if $\left[\left(P_{j}-R_{j}\right)^{\gamma}-\left(P_{j}-\bar{r}_{j}\right)^{\gamma}\right] A_{i j}-B_{j} \geq 0$.
} 
may not generate value to the firm (Holmstrom and Milgrom, 1991; Baker, 1992), further increasing the relative value of gifts.

This paper also provides insights concerning the profitability of gift giving within the firm. First, our results suggest that profitability will depend on the labor market conditions of the workers. Indeed, the value of gifts is predicted to increase in periods of economic downturn when workers have lower outside alternatives. Interestingly, these results parallel efficiency-wage models: Shapiro and Stiglitz (1984) and MacLeod and Malcomson (1989) derive efficiency wages as self-enforcing implicit contracts that best supply effort incentives within slack labour markets (when unemployment is high). Ackerlof's (1982) orginal work on gift exchange was largely attributed to the efficiency-wage literature, yet the mechanism here is very different; slack labour-market conditions allow a profit-maximizing firm to reduce the piece rate paid to their workers and still satisfy their participation constraints. In doing so, the marginal cost (in terms of effort) of responding to the gift is also reduced, increasing the effect of a gift on average worker productivity. Second, the composition of the monetary gift is predicted to have an important impact on its profitability. Our analysis has revealed that gifts should be provided in the form of above market clearing piece-rates as opposed to handing out (mostly unprofitable) fixed wages. This finding has implications for existing experimental results that have failed to find profitable base-wage gifts in environments with contractible output (Gneezy and List, 2006, for example). In such environments workers respond more strongly to piece-rate gifts than to base-wage gifts - piece-rate gifts may be more effective.

Our results also have implications for the analysis of experimental data. Experiments provide exogenous variation in contracts, simplifying the identification of treatment effects. Yet economists are increasingly calling for the generalization of experimental results. Applying economic models to experimental data allows for the identification of structural parameters, permits generalization and adds value to experiments. This is particularly useful when seeking to generalize in directions not attainable using experimental methods (such as different labour-market conditions).

Finally, we note that our model is static and neglects some dynamic issues associated with gift giving. Perhaps the most important is the rate at which gifts can, or should be dis- 
tributed by the firm. Our results suggest that gifts have an effect on worker productivity and can, under certain conditions, be profitable. Yet, an increasing body of evidence suggests that the effects of gifts are short term (Gneezy and List, 2006; Bellemare and Shearer, 2009). Whether or not gifts can form the basis of a profitable, long-term personnel policy or should only be used on special occasions remains a question for future research. 


\begin{tabular}{|l|l|l|l|l|}
\hline \hline \multicolumn{5}{|c|}{ Control Sample: 109 Observations } \\
\hline \hline \hline Variable & Average & Std. Deviation Gift & Minimum & Maximum \\
\hline \hline Number of Trees & 888.85 & 325.46 & 390 & 1765 \\
Piece Rate & 0.21 & 0.03 & 0.18 & 0.23 \\
Daily Earnings & 182.65 & 50.40 & 89.70 & 317.70 \\
\hline \hline \multicolumn{5}{|l|}{ Treatment Sample: 88 Observations } \\
\hline \hline Variable & Average & Std. Deviation Gift & Minimum & Maximum \\
\hline \hline Number of Trees & 1012.39 & 351.23 & 375 & 1965 \\
Piece Rate & 0.26 & 0.02 & 0.23 & 0.28 \\
Daily Earnings & 254.56 & 68.98 & 105.00 & 451.95 \\
\hline \hline
\end{tabular}

Table 1: Summary Statistics: Piece-Rate Experiment

\begin{tabular}{|l|l|l|l|l|}
\hline \hline \multicolumn{5}{|c|}{ Control Sample: 66 Observations } \\
\hline \hline Variable & Average & Std. Deviation Gift & Minimum & Maximum \\
\hline \hline Number of Trees & 1063.64 & 269.96 & 670 & 1625 \\
Piece Rate & 0.2 & 0 & 0.2 & 0.2 \\
Piece-Rate Earnings & 212.73 & 53.99 & 134 & 325 \\
Gift & 0 & 0 & 0 & 0 \\
Total Daily Earnings & 212.73 & 53.99 & 134 & 325 \\
\hline \hline \multicolumn{5}{|l|}{ Treatment Sample: 18 Observations } \\
\hline \hline Variable & Average & Std. Deviation Gift & Minimum & Maximum \\
\hline \hline Number of Trees & 1153.06 & 323.23 & 705 & 1845 \\
Piece Rate & 0.2 & 0 & 0.2 & 0.2 \\
Piece-Rate Earnings & 230.61 & 64.65 & 141 & 369 \\
Gift & 80 & 0 & 80 & 80 \\
Total Daily Earnings & 310.61 & 64.65 & 221 & 449 \\
\hline \hline
\end{tabular}

Table 2: Summary Statistics: Gift Experiment 


\begin{tabular}{|l|l|l|l|l|}
\hline \hline \multicolumn{5}{|c|}{ Control Sample: 678 Observations } \\
\hline \hline Variable & Average & Std. Deviation Gift & Minimum & Maximum \\
\hline \hline Number of Trees & 978.82 & 309.4249 & 210 & 2100 \\
Piece Rate & 0.23 & .04 & 0.16 & 0.35 \\
Piece-Rate Earnings & 219.57 & 59.25 & 48.30 & 420 \\
\hline \hline
\end{tabular}

Table 3: Summary Statistics: All Blocks 


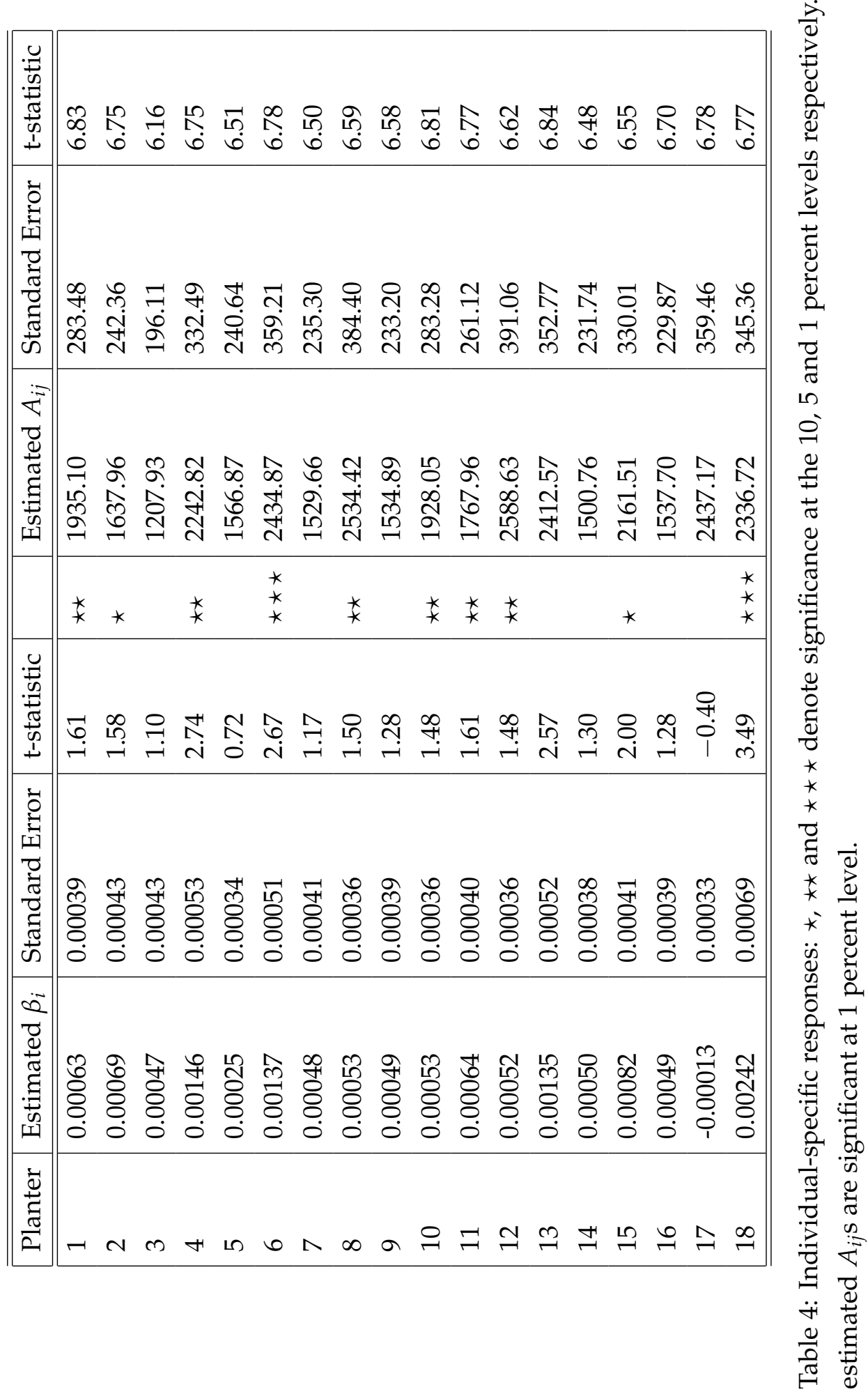




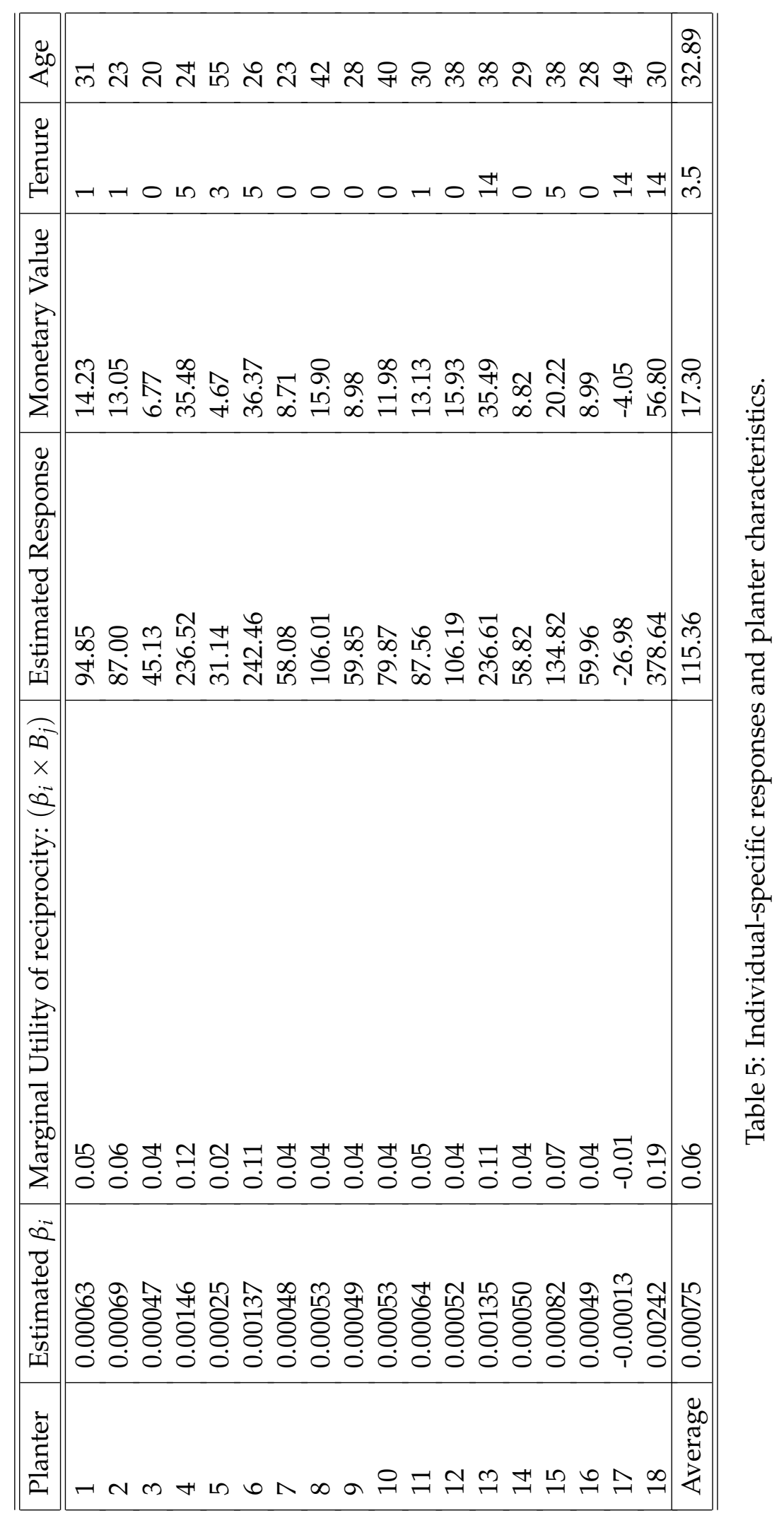


Figure 1: Piece-Rate and Gift-Giving Profits with piece-rate gifts under different labourmarket conditions $(\bar{r})$.

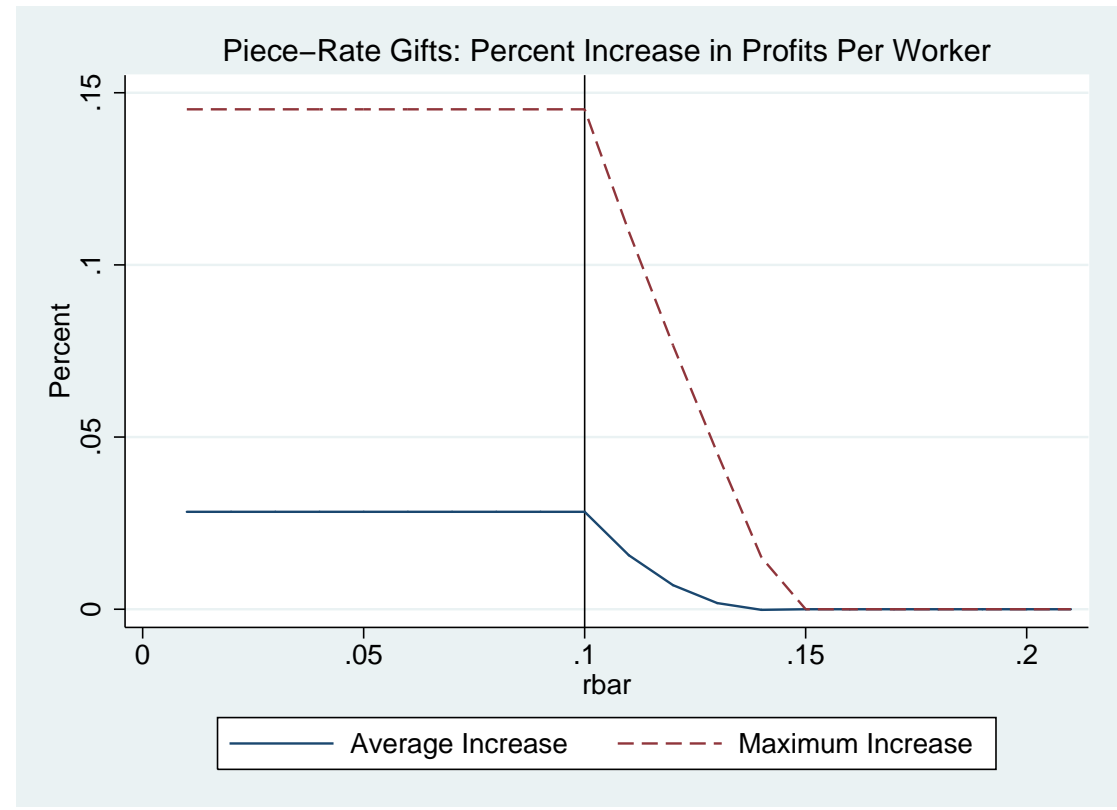

Figure 2: Percentiles of profit increases with piece-rate gifts under different labour-market conditions $(\bar{r})$.

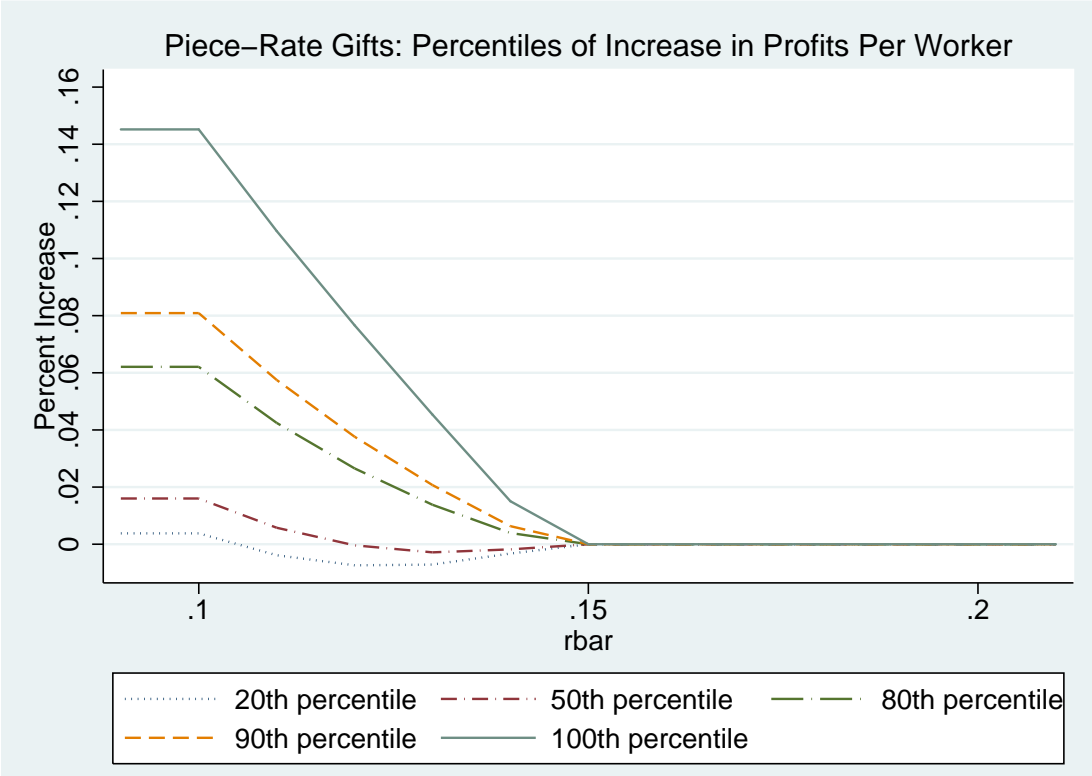


Figure 3: Average and Maximum Gifts with piece-rate gifts under different labour-market conditions $(\bar{r})$.

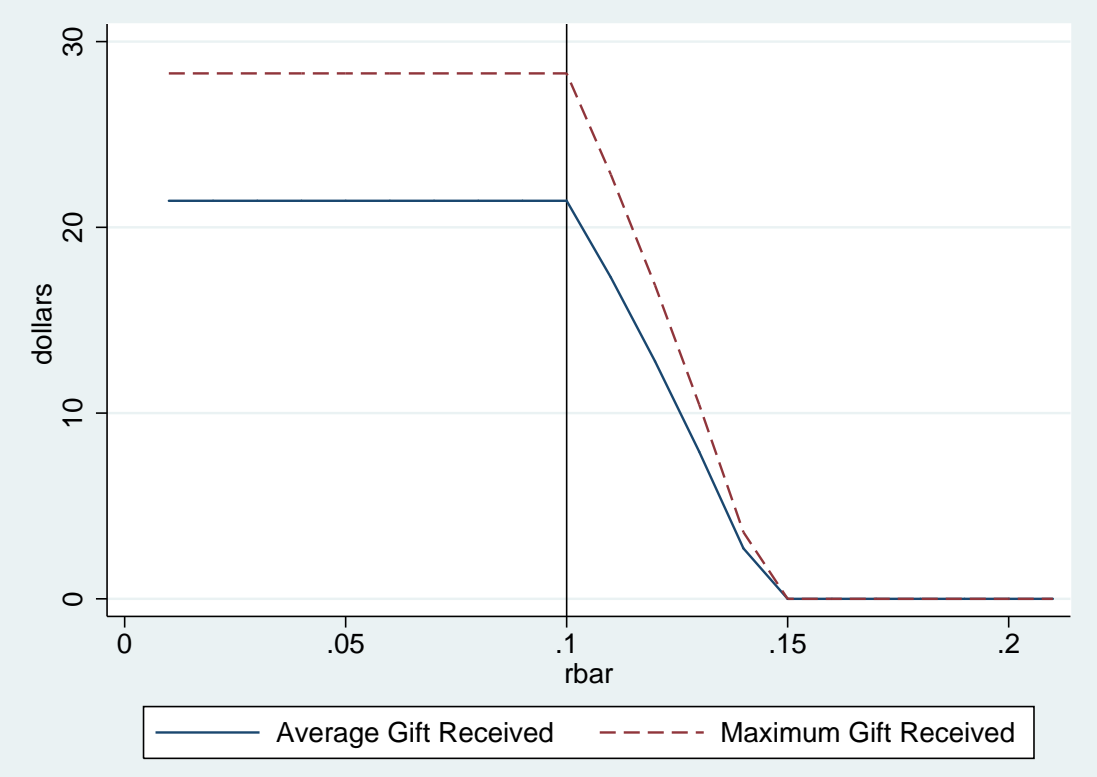

Figure 4: Gifts as proportion of earnings with piece-rate gifts under different labourmarket conditions $(\bar{r})$.

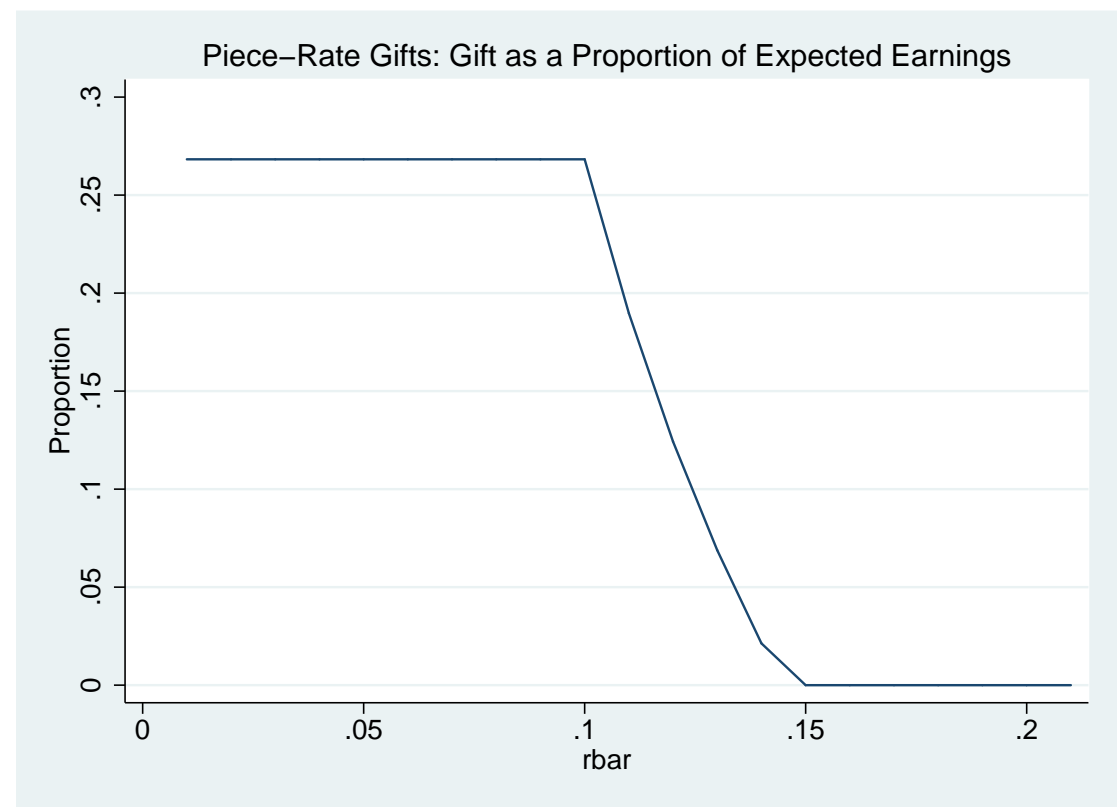


Figure 5: Piece-Rate and Gift-Giving Profits with composite gifts under different labourmarket conditions $(\bar{r})$.

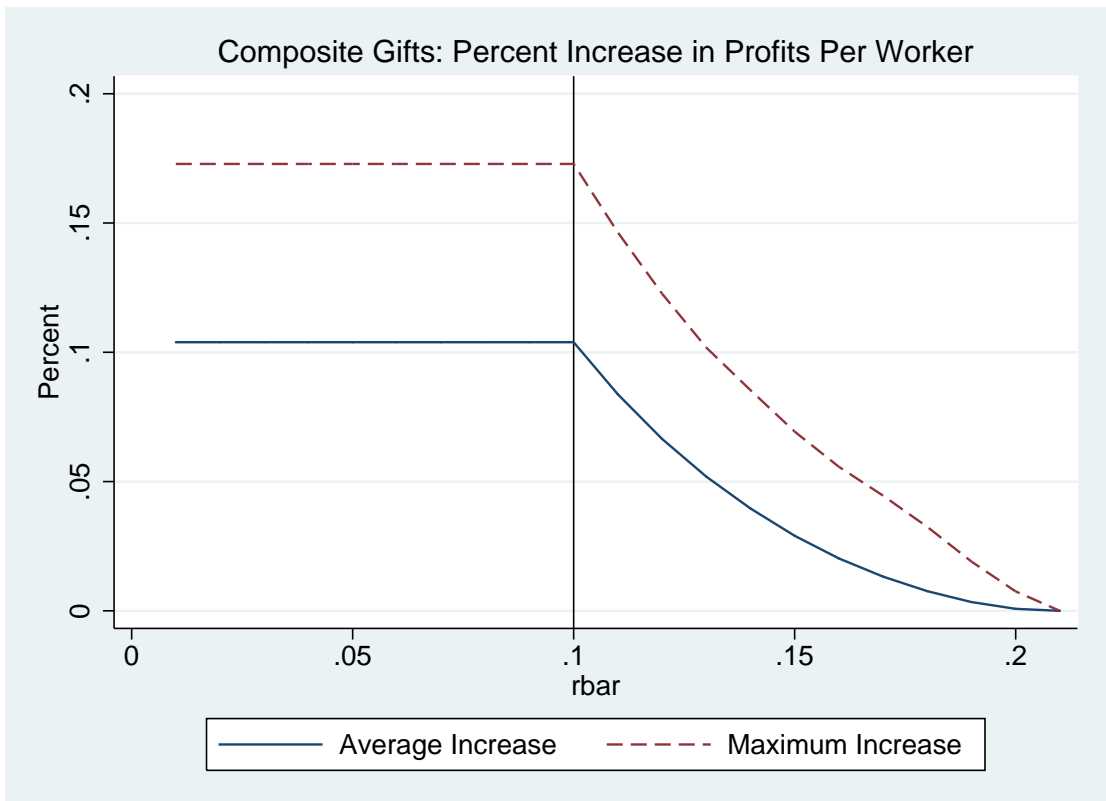

Figure 6: Percentiles of Profit Increases with composite gifts under different labour-market conditions $(\bar{r})$.

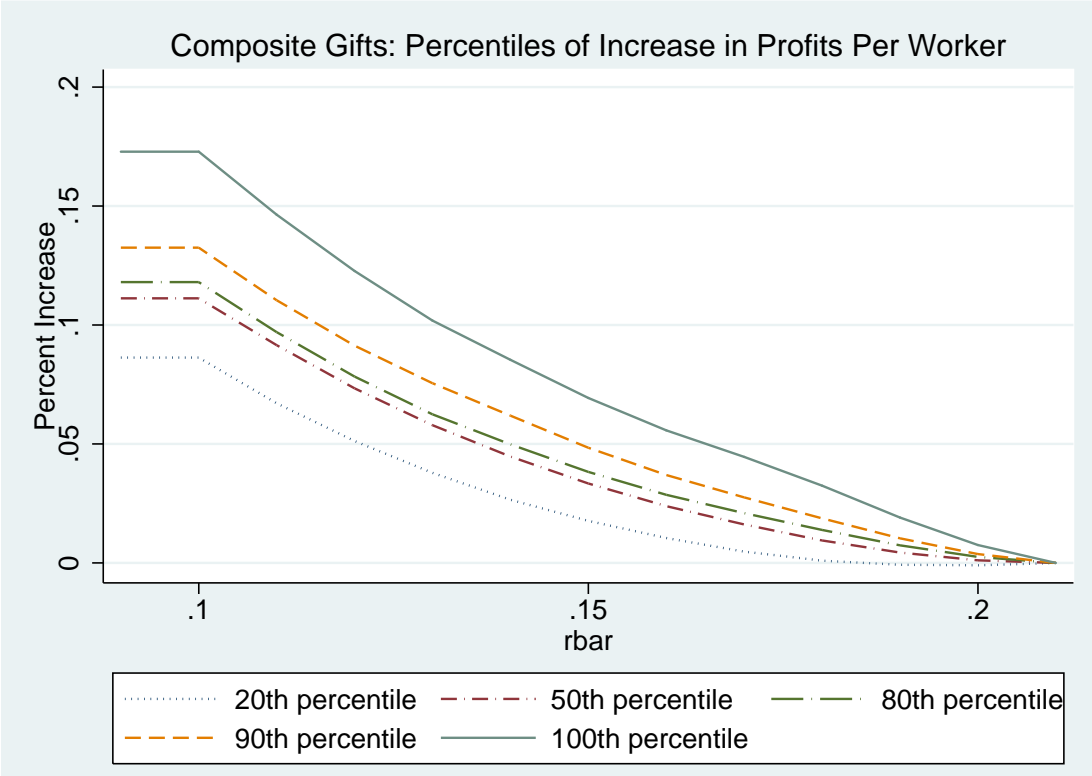


Figure 7: Average and Maximum Gifts with composite gifts under different labour-market conditions $(\bar{r})$.

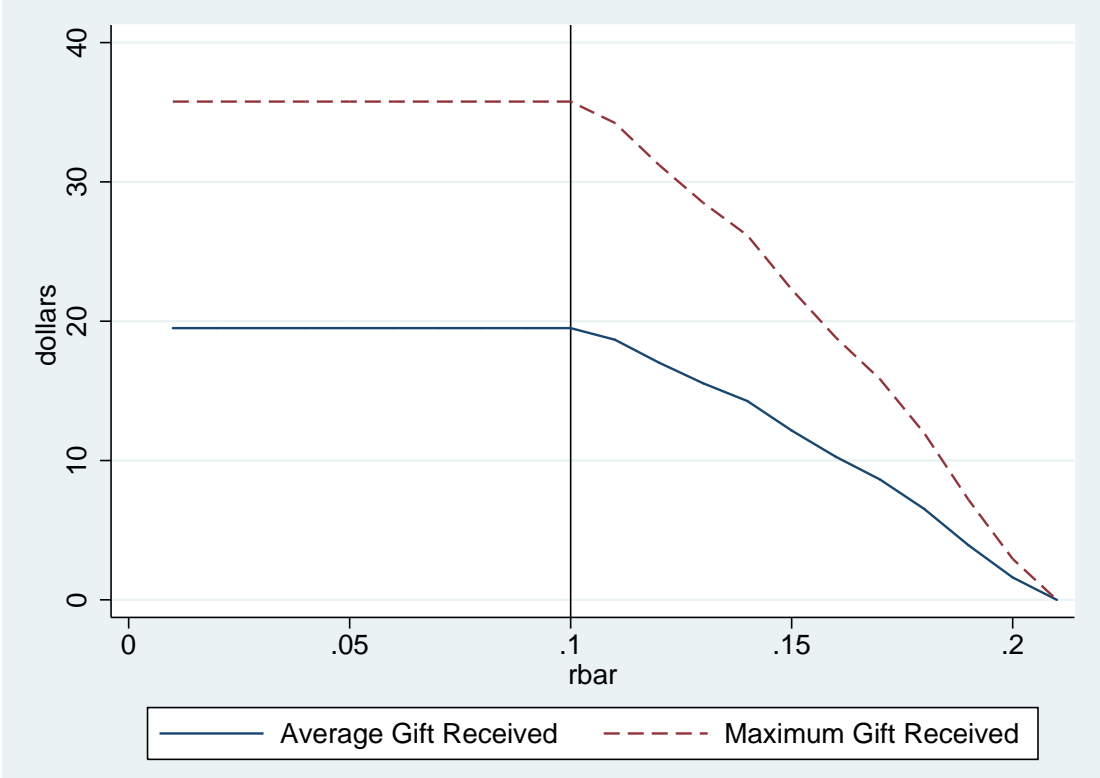

Figure 8: Gifts as proportion of earnings with composite gifts under different labourmarket conditions $(\bar{r})$.

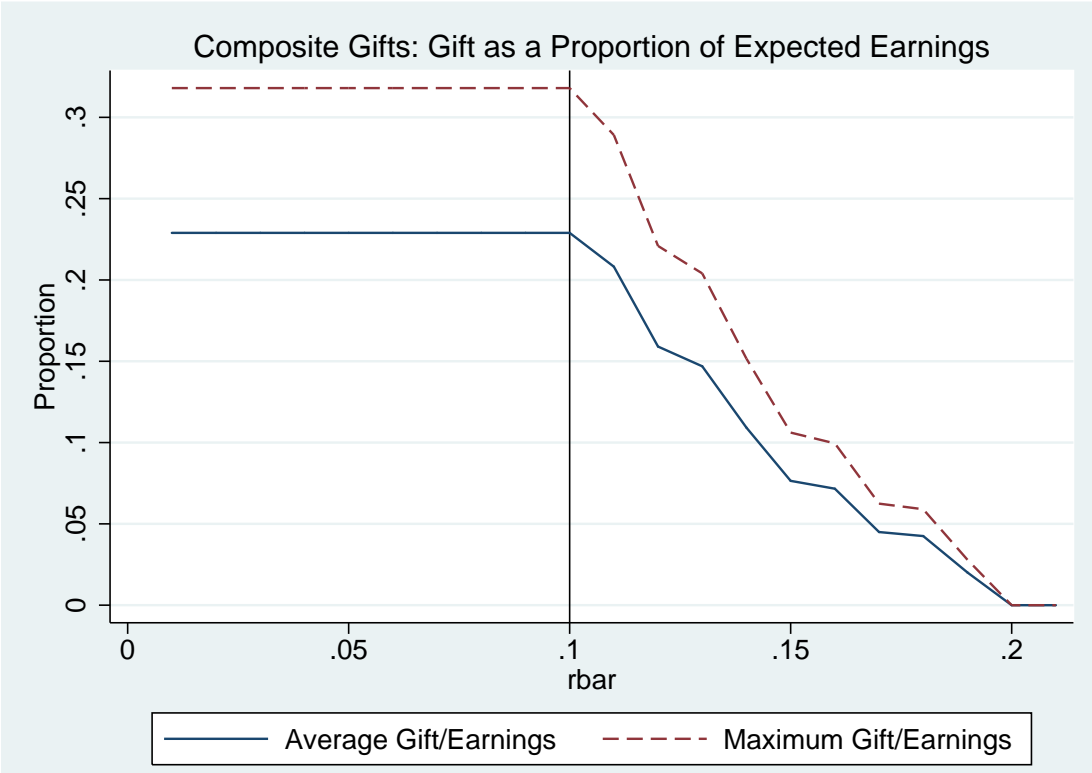


Figure 9: Composition of Gifts (The Piece Rate) with composite gifts under different labour-market conditions $(\bar{r})$.

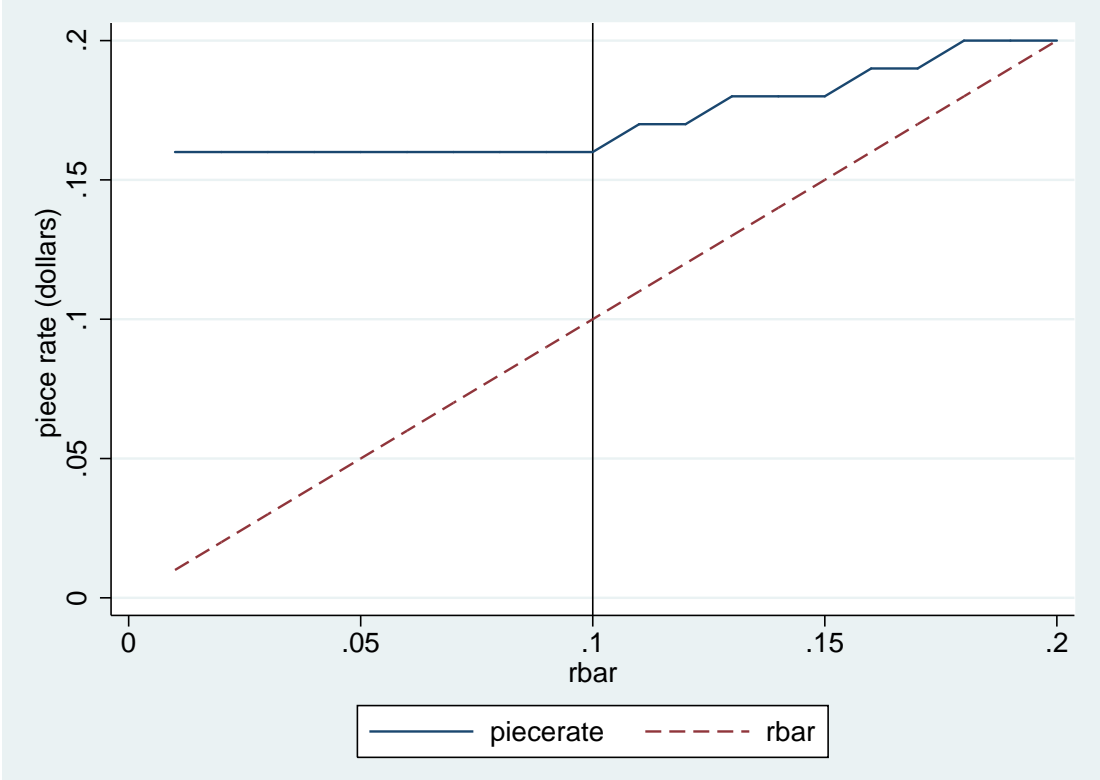

Figure 10: Composition of Gifts (The Base Wage) with composite gifts under different labour-market conditions $(\bar{r})$.

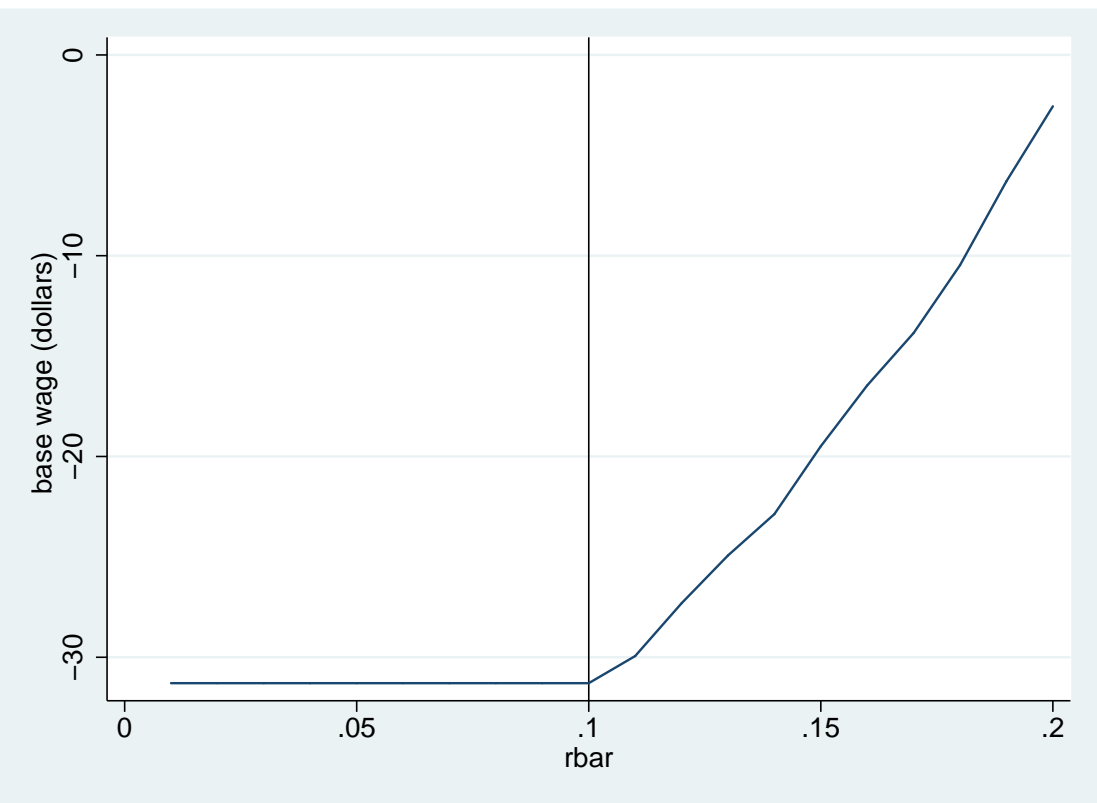




\section{References}

BAKer, E. (1992): “Performance Pay and Productivity," American Economic Review, 90, 1346-1361.

Bellemare, C., And B. Shearer (2009): “Gift Giving and Worker Productivity: Evidence from a Firm-level Experiment," forthcoming, Games and Economic Behavior.

Cameron, A. C., And P. K. Trivedi (2005): Microeconometrics. Cambridge University Press, New-York.

FEHR, E., AND A. FALK (2002): "Psychological Foundations of Incentives," European Economic Review, 46, 687-724.

FEHR, E., AND S. GÄCHTER (2002): “Do Incentive Contracts Undermine Voluntary Cooperation ?," IEW working paper 34.

Fehr, E., L. Goette, And C. Zehnder (2009): “A Behavioral Account of the Labor Market: The Role of Fairness Concerns," forthcoming, Annual Review of Economics.

Fehr, E., G. Kirchsteiger, And A. Riedl (1993): “Does Fairness Prevent Market Clearing? An Experimental Investigation," Quarterly journal of Economics, 153, 437-459.

GNeEZY, U., AND J. LIST (2006): “Putting Behavioral Economics to Work: field Evidence of Gift Exchange," Econometrica.

Heckman, J., AND J. Smith (1995): “Assessing the Case for Social Experiments," Journal of Economic Perspectives, 9(2), 85-110.

Holmstrom, B., And P. Milgrom (1991): "Multitask Principl-Agent Analyses: Incentive Contracts, Asses Ownership, and Job Design," Journal of Law, Economics and Organization, 7, 24-52.

LiSE, J., S. SEITZ, AND J. SMITH (2005): “Assessing the Case for Social Experiments," Boston College Working Paper.

MACleOD, B., AND J. MAlCOLMSON (1989): “Implicit Contracts, Incentitive Compatibility, and Involuntary Unemployment," Econometrica, 56(2), 447-480.

PAARSCH, H., AND B. SHEARER (2008): “The Response to Incentives and Contractual Efficiency: Evidence from a Field Experiment," European Economic Review, forthcoming.

RABIN (2006): "Incorporating Fairness into Game Theory and Economics," American Economic Review, 83(5), 1281-1302. 
SHAPIRO, C., AND J. STIGLITZ (1984): “Equilibrium Unemployment as a Worker Discipline Device," American Economic Review, 74(3), 433-444.

SHEARER, B. (2004): "Piece Rates, Fixed Wages and Incentive Effects: Evidence from a Field Experiment," Review of Economic Studies, 71.

TODD, P., AND K. WOLPIN (2006): “Assessing the Impact of a School Subsidy Program in Mexico: Using a Social Experiment to Validate a Dynamic Behavioral Model of Child Schooling and Fertility," American Economic Review, 96(5), 1384-1417. 